\title{
CD133 expression and identification of CD133/nestin positive cells in rhabdomyosarcomas and rhabdomyosarcoma cell lines
}

\author{
Jiri Sana $^{\mathrm{a}, 1}$, Iva Zambo ${ }^{\mathrm{b}, 1}$, Jan Skoda $^{\mathrm{a}, \mathrm{c}}$, Jakub Neradil $^{\mathrm{a}, \mathrm{c}}$, Petr Chlapek $^{\mathrm{a}, \mathrm{c}}$, Marketa Hermanova $^{\mathrm{b}}$, \\ Peter Mudry $^{\mathrm{c}}$, Alzbeta Vasikova ${ }^{\mathrm{d}}$, Karel Zitterbart ${ }^{\mathrm{c}}$, Ales Hampl ${ }^{\mathrm{e}}$, Jaroslav Sterba ${ }^{\mathrm{c}}$ \\ and Renata Veselska ${ }^{\mathrm{a}, \mathrm{c}, *}$ \\ ${ }^{a}$ Laboratory of Tumor Biology and Genetics, Department of Experimental Biology, School of Science, \\ Masaryk University, Brno, Czech Republic \\ ${ }^{\mathrm{b}} 1$ st Institute of Pathologic Anatomy, St. Anne's University Hospital and School of Medicine, \\ Masaryk University, Brno, Czech Republic \\ ${ }^{\mathrm{c}}$ Department of Pediatric Oncology, University Hospital Brno and School of Medicine, Masaryk University, \\ Brno, Czech Republic \\ ${ }^{\mathrm{d}}$ Center of Molecular Biology and Gene Therapy, Department of Internal Medicine - Hematooncology, \\ University Hospital Brno and School of Medicine, Masaryk University, Brno, Czech Republic \\ ${ }^{\mathrm{e}}$ Department of Histology and Embryology, School of Medicine, Masaryk University, Brno, Czech Republic
}

Received: January 4, 2011

Accepted: June 26, 2011

\begin{abstract}
Background: Co-expression of CD133, cell surface glycoprotein, and nestin, an intermediate filament protein, was determined to be a marker of neural stem cells and of cancer stem cells in neurogenic tumors.

Methods: We examined the expression of CD133 and nestin in ten tumor tissue samples taken from patients with rhabdomyosarcomas and in five rhabdomyosarcoma cell lines. Immunohistochemistry and immunofluorescence were used to examine FFPE tumor tissue samples. Cell lines were analyzed by immunofluorescence, immunoblotting, flow cytometry, and RT-PCR. Functional assays (clonogenic in vitro assay and tumorigenic in vivo assay) were also performed using these cell lines.

Results: CD133 and nestin were detected in all 10 tumor tissue samples and in all 5 cell lines; however, the frequency of CD133+, Nes+, and CD133+/Nes+ cells, as well as the intensity of fluorescence varied in individual samples or cell lines. The expression of CD133 and nestin was subsequently confirmed in all cell lines by immunoblotting. Furthermore, we observed an increasing expression of CD133 in relation to the cultivation. All cell lines were positive for Oct $3 / 4$ and nucleostemin; NSTS-11 cells were also able to form xenograft tumors in mice.

Conclusion: Our results represent the first evidence of CD133 expression in rhabdomyosarcoma tissue and in rhabdomyosarcoma cell lines. In addition, the co-expression of CD133 and nestin as well as results of the functional assays suggest a possible presence of cancer cells with a stem-like phenotype in these tumors.
\end{abstract}

Keywords: Rhabdomyosarcoma, CD133, nestin, cancer stem cells, stem cell related markers

\footnotetext{
${ }^{1}$ Both authors contributed equally to this work.

*Corresponding author: Renata Veselska, Laboratory of Tumor Biology and Genetics, Department of Experimental Biology, School of Science, Masaryk University, Kotlarska 2, 61137 Brno, Czech Republic. Tel.: +420 54949 7905; Fax: +420 54949 5533; E-mail: veselska@sci.muni.cz.
} 


\section{Introduction}

CD133 (also known as prominin-1) was originally described in two independent studies as a plasma membrane glycoprotein in mouse neuroepithelial stem cells and as an antigenic marker expressed on the CD34+population of hematopoietic stem cells in humans [21, 44]. This molecule contains five-transmembrane domains, two large glycosylated extracellular loops, an extracellular $\mathrm{N}$-terminus, and an intracellular C-terminus [21, 44, 46]. CD133 localizes to microvilli and other protrusions of the apical plasma membrane in various cell types $[6,44]$. Although the biological function of CD133 is still not known, the above-mentioned localization indicates that CD133 may act as an organizer of plasma membrane protrusions and affect cell polarity as well as interactions with nearby cells and with the extracellular matrix [5, 6, 9].

In humans, this protein is encoded by a gene on locus $4 \mathrm{p} 15.32$. The molecular weight of CD133 ranges from 89 to $120 \mathrm{kDa}$, depending on its glycosylation status $[12,13,32]$. However, truncated forms of CD133 with a lower molecular weight have been described recently [26, 41].

CD133, usually in combination with other specific markers, is widely used to identify stem cells in various human tissues, such as bone marrow [21, 46], CNS [40], prostate [29], or kidney [31]. Immunodetection has also showed that CD133 is frequently expressed in many types of human tumors and tumor cell lines; it was detected in cells from neurogenic tumors [33, 34], prostate carcinomas [4], hepatocellular carcinomas [35], renal carcinomas [3], colorectal carcinomas [28], melanomas [23], pancreatic adenocarcinomas [16], lung carcinomas [11], ovarian carcinomas [14], osteosarcomas [42], endometrial carcinomas [30], acute lymphoblastic leukemias [7], and synovial sarcomas [36].

At present, co-expression of glycosylated CD133 and nestin, a class VI intermediate filament protein, is considered to be a marker of cancer stem cells (CSCs) or tumor initiating cells (TICs). This was experimentally proven in glioblastoma multiforme $[19,27]$ and in melanoma [23]. Furthermore, the coexpression of CD133 and nestin was also shown in medulloblastomas [33], pilocytic astrocytomas [33], oligoastrocytomas [45], and in osteosarcomas [42].

Here, we present our results regarding CD133 and nestin expression in ten tumor tissue samples taken from patients with rhabdomyosarcomas and in five cell lines derived from these tumors.

\section{Material and methods}

\subsection{Tumor samples}

Ten samples of rhabdomyosarcoma tissues were included in this study. These samples were taken from seven patients ( 5 males, 2 females; age range: $2-21$ years old). Formalin-fixed and paraffin-embedded (FFPE) surgical samples of neoplastic tissues were retrieved from the files of the Department of Pathology, University Hospital Brno, Czech Republic, and of the Department of Oncological and Experimental Pathology, Masaryk Memorial Cancer Institute, Brno, Czech Republic. Histological sections stained with hematoxylin-eosin (H-E) were reviewed by two pathologists (IZ and $\mathrm{MH}$ ), and representative tissue blocks were selected for immunohistochemical and immunofluorescence analysis. Cell lines were derived from respective biopsy samples that were taken from patients surgically treated for rhabdomyosarcoma; all samples for cell cultures were coded and processed in the laboratory in an anonymous manner. The Research Ethics Committee of the University Hospital Brno approved the study protocol, and a written statement of informed consent was obtained from each participant prior to their participation in this study. A description of the cohort of patients included in this study is provided in Table 1.

\subsection{PCR analysis of the tumor samples}

Reverse transcriptase (RT) two-step nested PCR for fusion transcript PAX3-FKHR and one-step RT-PCR for fusion transcript PAX7-FKHR were used according to published methods $[1,37]$. Briefly, extraction of total RNA from a patient's tumor samples was performed using an RNeasy Mini Kit (Qiagen, Hilden, Germany) according to the instruction manual. An initial amount of $1 \mu \mathrm{g}$ RNA was used for reverse transcription using random hexamers and MuLV reverse transcriptase (Applied Biosystems, Foster City, CA, USA). PCR products were electrophoresed on a $2 \%$ agarose gel and visualized after ethidium bromide staining. For all positive assays, the PCR product was confirmed by standard direct nucleotide sequencing.

\subsection{Cell cultures}

Starting with primary cultures, fresh specimens of tumor tissue were processed as described previously 
Table 1

Description of patient cohort and characterization of analyzed tumors

\begin{tabular}{lccccccc}
\hline $\begin{array}{l}\text { Tumor } \\
\text { sample }\end{array}$ & Gender & Age & $\begin{array}{c}\text { Tumor } \\
\text { type }\end{array}$ & $\begin{array}{c}\text { Time of } \\
\text { biopsy }\end{array}$ & $\begin{array}{c}\text { Translocation in } \\
\text { tumor tissue }\end{array}$ & Cell line & $\begin{array}{c}\text { Translocation in } \\
\text { cell line }\end{array}$ \\
\hline 1 & M & 13 & A & DG & positive PAX3/FKHR & - & - \\
2 & M & 17 & A & DG & positive PAX3/FKHR & NSTS-09 & $21.3 \%$ \\
3 & F & 16 & E & NACHT & negative PAX3,PAX7/FKHR & NSTS-11 & $2.7 \%$ \\
4 & M & 7 & E & DG & negative PAX3,PAX7/FKHR & - & - \\
5 & F & 2 & E & DG & negative PAX3,PAX7/FKHR & NSTS-12 & $2.3 \%$ \\
6 & M & 2 & A & DG & positive PAX3/FKHR & - & - \\
$7 \mathrm{a}$ & F & 21 & A & DG & positive PAX3/FKHR & NSTS-08 & $22.3 \%$ \\
$7 b$ & & & & NACHT & not available & NSTS-10 & $20.3 \%$ \\
$7 \mathrm{c}$ & & & & PROG & positive PAX3/FKHR & - & - \\
$7 \mathrm{~d}$ & & & & PROG & not available & - & - \\
\hline
\end{tabular}

Notes: Gender: M, male; F, female. Age at the time of diagnosis: years. Tumor type: A, alveolar; E, embryonal. Time of biopsy: DG, diagnostic; NACHT, after neo-adjuvant chemotherapy; PROG, progression of the disease. Translocation in tumor tissue: translocation PAX3/PAX7-FKHR as detected by RT-PCR analysis. Translocation in cell line: FKHR break of as detected by FISH analysis.

$[42,43]$. The primary cultures were maintained in DMEM supplemented with $20 \%$ fetal calf serum, $2 \mathrm{mM}$ glutamine, and antibiotics: $100 \mathrm{IU} / \mathrm{ml}$ penicillin and $100 \mu \mathrm{g} / \mathrm{ml}$ streptomycin (all purchased from PAA Laboratories, Linz, Austria) and cultivated under standard conditions at $37^{\circ} \mathrm{C}$ in an atmosphere of $95 \%$ air : $5 \% \mathrm{CO}_{2}$. Once the specimen pieces had attached, the volume of the medium was gradually increased to $5 \mathrm{ml}$ over the next 48 hours. As soon as the outgrowing cells covered approximately $60 \%$ of the surface, they were trypsinized, diluted, and transferred into a new flask. A similar procedure was used for further subcultivations of all cell lines that were derived from the primary cultures.

\subsection{FISH analysis of the cell lines}

Using Poseidon ${ }^{\mathrm{TM}}$ probes ON FKHR Break (Kreatech Diagnostics, Amsterdam, Netherlands), we examined all the above described rhabdomyosarcoma cell lines. For FISH analysis, cell suspensions were hypotonized with $75 \mathrm{mM} \mathrm{KCl}$ and fixed in methanol/acetic acid (3:1, vol:vol). Cell suspensions were spread onto microscopic slides and chemically aged in $2 \times \mathrm{SSC}$ for $30 \mathrm{~min}$ at $37^{\circ} \mathrm{C}$. The slides were then dehydrated in $70 \%, 80 \%$, and $96 \%$ ethanol for 2 min each and air-dried. Codenaturation was performed for $5 \mathrm{~min}$ at $75^{\circ} \mathrm{C}$, and following hybridization, was allowed to proceed overnight at $37^{\circ} \mathrm{C}$. Hybridized slides were then washed sequentially in $0.5 \times \mathrm{SSC}$ for $3 \mathrm{~min}$ at $75^{\circ} \mathrm{C}$ and $2 \times \mathrm{SSC}$ for $1 \mathrm{~min}$ at room temperature and were mounted in DAPI Counterstain (Kreatech). An Olympus BX-61 microscope was used for FISH evaluation. Micrographs were captured by Vosskühler 1300D CCD camera and analyzed using Lucia 4.80 - KARYO/FISH/CGH software (Laboratory Imaging, Prague, Czech Republic). At least 150, but most often 300 , interphase nuclei were scored for FKHR (13q14) gene status.

\subsection{FFPE immunohistochemistry}

Immunohistochemical detection of both nestin and CD133 was performed on $4 \mu \mathrm{m}$ thick tissue sections applied to positively charged slides. The sections were deparaffinized in xylene and rehydrated through a graded alcohol series. Antigen retrieval was performed in a Pascal calibrated pressure chamber (DAKO, Glostrup, Denmark) by heating the sections in modified citrate buffer (DAKO) at pH 6.1 (CD133 IHC) or in Tris/EDTA buffer (DAKO) at pH 9.0 (nestin IHC) for $40 \mathrm{~min}$ at $97^{\circ} \mathrm{C}$. Endogenous peroxidase activity was quenched in $3 \%$ hydrogen peroxide in methanol for $10 \mathrm{~min}$, followed by incubation at room temperature with a rabbit polyclonal antibody against CD133 (No. ab19898, dilution 1:200, Abcam, Cambridge, UK) for $60 \mathrm{~min}$ or a mouse monoclonal antibody against nestin (clone 10C2, dilution 1:200, Millipore, Billerica, MA, USA) for $90 \mathrm{~min}$. A streptavidin-biotin peroxidase detection system was used according to the manufacturer's instructions (Vectastain Ellite ABC Kit, Vector Laboratories, Burlingame, CA, USA); 3,3'diaminobenzidine was used as a chromogen (DAB, DAKO). Slides were counterstained with Gill's hematoxylin. Tissue sections of glioblastoma multiforme served as external positive controls for the anti-nestin 
antibody; Nes+ or CD133+ endothelial cells in rhabdomyosarcoma tissue samples were used as internal positive controls. Negative controls were prepared by incubating samples without primary antibody. Evaluation of immunohistochemical results was performed using a uniform microscope and camera setting (Olympus BX51 microscope and DP70 camera).

\subsection{Evaluation of FFPE immunohistochemistry}

For CD133, only specific membranous positivity was scored; however, cytoplasmic immunopositivity was observed in a variable proportion of tumor cells in all examined samples (see explanation in discussion). For nestin, cytoplasmic immunostaining was regarded as positive. The intensity of staining and the percentages of positive tumor cells (TC) were evaluated by two pathologists (IZ and $\mathrm{MH}$ ) independently, using a light microscope at $\times 400$ magnification. At least five discrete foci of neoplastic infiltration were analyzed, and the average staining intensity and the percentage of CD133+ or Nes+ cells of the entire covered area were determined. The percentage of $\mathrm{CD} 133+$ or Nes+ TC was categorized into four levels: $\pm(<2 \% \mathrm{CD} 133+$ or Nes+ TC $),+(2-10 \% \mathrm{CD} 133+$ or Nes+ TC), ++ (11-50\% CD133+ or Nes+ TC), and +++ (51-100\% CD133+ or Nes+ TC). The intensity of immunostaining was graded as very weak $( \pm)$, weak $(+)$, medium $(++)$, and strong $(+++)$. The intensity of immunostaining was also evaluated in endothelial cells, which were used as an internal positive control.

\subsection{FFPE immunofluorescence}

After deparaffinization and rehydration of the tissue sections, antigen retrieval was carried out under same conditions as mentioned above. Rabbit polyclonal antiCD133 antibody (No. ab19898, dilution 1 : 50, Abcam) or mouse monoclonal anti-nestin antibody (clone $10 \mathrm{C} 2$, dilution $1: 200$, Millipore) were used as primary antibodies. Tissue sections were incubated with primary antibodies at room temperature for $30 \mathrm{~min}$ or $90 \mathrm{~min}$, respectively. Then appropriate secondary antibodies, i.e., goat anti-rabbit antibody conjugated with TRITC (No. TI-1000, dilution $1: 100$, Vector) or goat anti-mouse antibody conjugated with FITC (No. AP124F, dilution 1:50, Millipore) were applied for $45 \mathrm{~min}$ or $60 \mathrm{~min}$, respectively. Subsequently, slides were mounted with mounting medium (No. S3025, Faramount Aqueous Mounting Medium, DAKO). A uniform microscope and camera setting (Nikon Eclipse 80i microscope and DS-Fil camera) was used for the evaluation of immunofluorescence results. Micrographs were analyzed using NIS-Elements BR 3.0 software (Laboratory Imaging).

\subsection{Evaluation of FFPE immunofluorescence}

Both for CD133 and nestin, the frequency of clearly positive cells (membranous positivity for CD133 and cytoplasmic positivity for nestin) was determined as follows: + (sporadically positive TC), ++ (dispersedly positive TC) and +++ (abundant positive TC). In CD133 immunofluorescence, weak cytoplasmic positivity was observed in sporadic TC in all examined cases. The slides were evaluated by two pathologists (IZ and $\mathrm{MH}$ ) independently, using a fluorescent microscope at $\times 400$ magnification.

\subsection{Immunofluorescence of cell lines}

To immunostain for CD133 and nestin, cell suspensions at a concentration of $10^{4}$ cells per ml were seeded on glass coverslips and grown under standard conditions for $24 \mathrm{~h}$. Cells were then washed in PBS, fixed with 3\% para-formaldehyde (Sigma-Aldrich, St. Louis, USA) in PBS for $20 \mathrm{~min}$ at room temperature. The cells were subsequently washed in PBS and incubated for $10 \mathrm{~min}$ with $2 \% \mathrm{BSA}$ (PAA) to block nonspecific binding of the secondary antibodies. CD133 and nestin were visualized by indirect immunofluorescence. Rabbit polyclonal anti-CD133 antibody (No. ab19898, dilution 1:100, Abcam) and mouse monoclonal human-specific anti-nestin antibody (clone 10C2, dilution 1:200, Millipore) were used as primary antibodies. The cells were treated with primary antibodies at $37^{\circ} \mathrm{C}$ for $1 \mathrm{~h}$ and washed three times in PBS. Corresponding secondary antibodies, i.e., anti-rabbit antibody conjugated with TRITC (No. T6778, dilution $1: 160$, Sigma) or anti-mouse antibody conjugated with FITC (No. F8521, dilution $1: 160$, Sigma), were applied under the same conditions. Finally, the cells were mounted onto glass slides in Vectashield mounting medium containing DAPI (Vector). The cells were observed using an Olympus BX-61 fluorescence microscope. Micrographs were captured with a CCD camera COHU 4910 and ana- 
lyzed using Lucia 4.80 software - KARYO/FISH/CGH (Laboratory Imaging, Prague, Czech Republic).

\subsection{Evaluation of immunofluorescence on cell lines}

The percentage and intensity of immunostaining (immunoreactivity) of CD133+ or Nes+ cells were evaluated at discrete areas of each sample. The samples were prepared from several various passages of all examined cell lines. The average percentage of positive cells and the intensity of immunostaining were determined for entire samples of individual cell lines. The percentage of CD133+ or Nes+ cells was categorized into six levels: $(+), \sim 1 \% \mathrm{CD} 133+$ or Nes+ cells; + , $1-10 \%$ CD133+ or Nes+ cells; +(+), $10 \%$ CD133+ or Nes+ cells; ++, 10-50\% CD133+ or Nes+ cells; $++(+), \sim 50 \% \mathrm{CD} 133+$ or Nes+ cells; +++, $>50 \%$ CD133+ or Nes+ cells. The intensity of immunostaining (immunoreactivity) was categorized into three levels: +, weak; ++, medium; +++, strong.

\subsection{Flow cytometry}

Cell suspensions at identical concentrations were seeded onto Petri dishes $\left(60 \mathrm{~cm}^{2}\right)$ and grown under standard conditions. Evaluation of CD133 expression was performed from the second to the sixth day of cultivation at $24 \mathrm{~h}$ intervals. For CD133 and isotype control cell surface indirect immunostaining, cells were detached using $1 \mathrm{mM}$ EDTA (PAA), fixed with 3\% para-formaldehyde (Sigma) in PBS overnight at $4^{\circ} \mathrm{C}$ and then washed in PBS. The cells were treated either with rabbit polyclonal anti-CD133 primary antibody (No. ab19898, Abcam) or rabbit polyclonal isotype control (No. ab37416, Abcam) at $6 \mu \mathrm{g} / \mathrm{ml}$ for $40 \mathrm{~min}$ at $4^{\circ} \mathrm{C}$ and washed in PBS. Anti-rabbit IgG conjugated with FITC (No. F9887, dilution 1:160, Sigma) was applied as a secondary antibody under the same conditions. Cytometric analysis was performed using a FACS Canto ${ }^{\mathrm{TM}}$ II (BD Biosciences). Ten thousand events per sample were evaluated using WinMDI 2.8 software. After completion of the flow cytometric analysis, the remaining cell suspensions were mounted onto glass slides and observed using a Nikon Eclipse 80i fluorescence microscope in combination with a DSFil camera. Micrographs were taken at $24 \mathrm{~h}$ intervals using the same microscope and camera settings.

\subsection{Immunoblotting}

Whole-cell extracts were loaded onto polyacrylamide gels, electrophoresed, and blotted onto polyvinylidene difluoride membranes (Bio-Rad Laboratories $\mathrm{GmbH}$, Germany). The membranes were blocked with 5\% nonfat milk in PBS with $0.1 \%$ Tween 20 (PBS-T), then incubated either with rabbit polyclonal anti-CD133 primary antibody (No. ab19898, Abcam), mouse monoclonal anti-nestin primary antibody (clone 10C2, Millipore) or mouse monoclonal anti-alpha tubulin primary antibody (clone TU-01, Exbio, Prague, Czech Republic) diluted 1:1000 in blocking solution at $4{ }^{\circ} \mathrm{C}$ overnight. After rinsing with PBS-T, the membranes were incubated with corresponding secondary antibodies at room temperature for $45 \mathrm{~min}$; i.e., anti-mouse IgG antibody peroxidase conjugate (No. A9917, Sigma) or anti-rabbit IgG antibody peroxidase conjugate (No. A2074, Sigma) diluted $1: 5000$. Each step was followed by at least three 10-min washes in PBS-T. ECL-Plus detection was performed according to the manufacturer's instructions (Amersham, GE Healthcare, UK).

\subsection{PCR analysis of the cell lines}

For RT-PCR, total RNA was extracted with GenElute $^{\mathrm{TM}}$ Mammalian Total RNA Miniprep Kit (Sigma-Aldrich). For all samples, equal amounts of RNA (25 ng of RNA per $1 \mu$ l of total reaction content) was reverse transcribed into cDNA using M-MLV (Top-Bio, Prague, Czech Republic) and oligo-dT (Qiagen) priming. PCR was carried out in $50 \mu \mathrm{l}$ reactions containing $0,5 \mu \mathrm{M}$ of each primer and $10 \mu \mathrm{l}$ of diluted cDNA. Following primer sequences were used: Oct3/4, 5'-GCAAAGCAGAAACCCTCGT-3' (forward) and 5'-ACACTCGGACCACATCCTTC-3' (reverse); Nucleostemin, 5'-TGCGAAGTCCAGCAA GTATTG-3' (forward) and 5'-AATGAGGCACCTGT CCACTC-3' (reverse); GAPDH, 5'-AGCCACATCGC TCAGACACC-3' (forward) and 5'-GTACTCAGCGC CAGCATCG- $3^{\prime}$ (reverse). PCR conditions include a first step of 4 minutes at $94^{\circ} \mathrm{C}$, a second step of 30 cycles of 30 seconds at $94^{\circ} \mathrm{C}, 30$ seconds annealing step at $60^{\circ} \mathrm{C}, 45$ seconds at $72^{\circ} \mathrm{C}$ and a final step of 5 minutes at $72^{\circ} \mathrm{C}$. Final products were examined by gel electrophoresis on $1 \%$ agarose. 


\subsection{Clonogenicity assay in vitro}

The cells were trypsinized, single cells were manually transferred with a micropipette under microscope into separate wells of 96-well microtiter plates and were cultivated under standard conditions (see 2.3. for details). A capability of cells to proliferate and to form colonies was examined every two days for two weeks and documented using an Olympus CKX41 inverted microscope in combination with an Olympus SP-350 camera.

\subsection{Tumorigenicity assay in vivo}

Enzymaticaly dissociated cell suspension of NSTS11 cells at concentration of $1.5 \times 10^{6}$ cells per $100 \mu \mathrm{l}$ was injected subcutaneously in three 8-week-old female NOD/SCID mice. The mice were examined every three days for the presence of subcutaneous tumors. After appearance of the tumors, the mice were sacrificed and tumor tissue was collected. Each tumor was dissected into two equal parts: one of them was processed for primary culture (see 2.3.), the second was fixed in $10 \%$ buffered formalin for 24 hours, routinely processed for histological examination and embedded in paraffin. Tissue sections of FFPE samples were stained with $\mathrm{H}-\mathrm{E}$ and examined. Immunohistochemical analysis was performed (see 2.5. and 2.6. for details). Monoclonal mouse anti-human desmin (clone
D33, dilution $1: 100$, DAKO), monoclonal mouse antihuman muscle actin (clone HHF35, dilution 1:50, DAKO) and polyclonal rabbit anti-human myoglobin (dilution 1:500, Novocastra Lab., Newcastle upon Tyne, UK) were employed to confirm myogenic differentiation of xenograft tumors. For desmin IHC, antigen retrieval was performed in a Pascal calibrated pressure chamber (DAKO) by heating the section in modified citrate buffer at $\mathrm{pH}$ 6.1. Myoglobin and muscle actin IHC was performed without antigen retrieval. The incubation time for all these primary antibodies was 60 minutes. A peroxidase conjugated polymer detection system was used for desmin, muscle actin and myoglobin detection (EnVision ${ }^{\mathrm{TM}}+$ Dual Link, HRP rabbit/mouse, DAKO), 3,3'-diaminobenzidine was used as a chromogen (DAB, DAKO). Detection of nestin and CD133 in xenograft tumors was performed as described above (see 2.5. and 2.6. for details).

\section{Results}

\subsection{CD133 and nestin detection in the rhabdomyosarcoma tumor tissue}

The results of nestin and CD133 expression in rhabdomyosarcomas by immunohistochemical (IHC) and immunofluorescence (IF) detection are summarized in Table 2.

Table 2

Immunohistochemical and immunofluorescence analysis of CD133 and nestin expression in rhabdomyosarcomas

\begin{tabular}{|c|c|c|c|c|c|c|c|c|c|}
\hline \multirow[t]{2}{*}{ Tumor sample } & \multirow[t]{2}{*}{ Tumor type } & \multirow[t]{2}{*}{ IF CD133 } & \multicolumn{3}{|c|}{ IHC CD133 } & \multirow[t]{2}{*}{ IF Nestin } & \multicolumn{3}{|c|}{ IHC Nestin } \\
\hline & & & $\% \mathrm{TC}$ & IR TC & IR EC & & $\% \mathrm{TC}$ & IR TC & IR EC \\
\hline 1 & A & + & \pm & +++ & +++ & +++ & +++ & + & + \\
\hline 2 & A & + & \pm & +++ & ++ & +++ & ++ & + & ++ \\
\hline 3 & $\mathrm{E}$ & + & \pm & + & ++ & + & ++ & + & + \\
\hline 4 & $\mathrm{E}$ & + & + & + & ++ & + & ++ & ++ & ++ \\
\hline 5 & $\mathrm{E}$ & + & \pm & ++ & +++ & ++ & +++ & + & \pm \\
\hline 6 & A & + & \pm & +++ & +++ & +++ & +++ & + & + \\
\hline $7 \mathrm{a}$ & & + & \pm & ++ & +++ & ++ & +++ & ++ & \pm \\
\hline $7 b$ & A & + & \pm & ++ & +++ & ++ & +++ & ++ & ++ \\
\hline $7 \mathrm{c}$ & & + & \pm & +++ & +++ & +++ & +++ & + & + \\
\hline $7 d$ & & + & \pm & ++ & +++ & ++ & +++ & + & + \\
\hline
\end{tabular}

Notes: Expression of CD133 and nestin was examined on formaline-fixed, paraffin embedded tissue samples of rhabdomyosarcomas using both immunofluorescence (IF) and immunohistochemistry (IHC). Evaluation of IF: + (sporadically positive TC), ++ (dispersedly positive TC) and +++ (abundant positive TC). Evaluation of IHC: \% TC, percentage of nestin-positive or CD133-positive tumor cells $( \pm,<2 \% ;+, 2-10 \% ;++, 11-50 \% ;+++, 51-100 \%)$. IR TC, intensity of immunostaining (immunoreactivity) in tumor cells ( \pm , very weak; + , weak; ++ , medium; +++, strong). IR EC, intensity of immunostaining (immunoreactivity) in endothelial cells ( \pm , very weak; + , weak; ++ , medium; +++ , strong). Tumor type: A, rhabdomyosarcoma, alveolar type; E, rhabdomyosarcoma, embryonal type. 

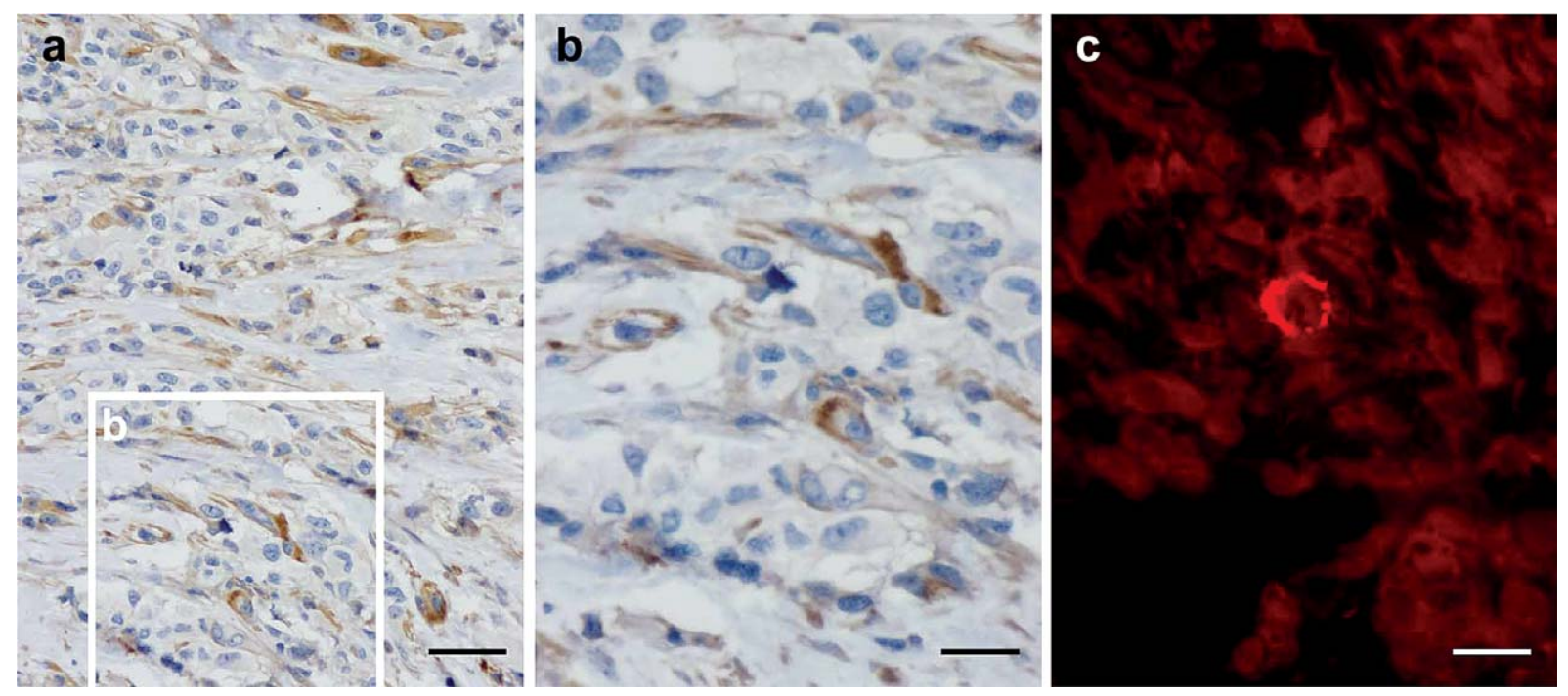

Fig. 1. Immunohistochemical and immunofluorescence analysis of CD133 expression in rhabdomyosarcomas tissues. Both IHC (a, b) and IF (c) revealed membranous CD133 positivity in only small number of tumor cells. Nonspecific cytoplasmic positivity was revealed in a significant proportion of tumor cells $(a, b)$. Immunohistochemistry with Gill's hematoxylin counterstain (a, b); indirect immunofluorescence using TRITC-labeled secondary antibody (c). Bars, $100 \mu \mathrm{m}$ (a), $50 \mu \mathrm{m}$ (b), $50 \mu \mathrm{m}$ (c).

In all examined cases, IF detection of membranous CD133 positivity was revealed in only a few tumor cells dispersed throughout the tumor tissues (Fig. 1c). Both CD133 IHC (Fig. 1b) and IF revealed not only membranous positivity in sporadic tumor cells, but also a nonspecific cytoplasmic positivity in a variable proportion of tumor cells (Fig. 1a).

Nestin expression was identified using both IHC and IF in all examined tumor samples (Fig. 2). The intensity of cytoplasmic IHC staining varied from strong (Fig. 2a) to weak (Fig. 2b). Similarly, the frequency of positive tumor cells revealed both by IHC and IF ranged from a strong, diffuse positivity (Fig. 2a and c) to a sporadic, medium to weak cytoplasmic nestin immunostaining in a subset of tumor cells (Fig. $2 \mathrm{~b}$ and d).

\subsection{Expression of CD133 and nestin in rhabdomyosarcoma cell lines}

CD133 was observed in the form of a clear, membranous signal in all five newly derived rhabdomyosarcoma cell lines using indirect immunofluorescence (Table 3, Fig. 3). However, the percentage and the intensity of immunostaining (immunoreactivity) of CD133+ cells varied among individual cell lines (Table 3, Fig. 3c and d). The presence of CD133 was subsequently verified using immunoblotting, and a 75$\mathrm{kDa}$ band specific for CD133 was detected in all five cell lines examined (Fig. 4a).

Furthermore, using the NSTS-11 cell line, we experimentally determined that CD133 expression in cell populations seeded at the same concentrations increased over the course of a six-day cultivation (Fig. 5). Using a fluorescence microscope, we observed an increase of CD133+ fluorescence intensity in individual cells (Fig. 5a). The same results were also achieved by immunoblotting (Fig. 5b). Using flow cytometry, approximately a 193 percent increase in CD133 fluorescence intensity (FI) was noted from day 2 to day 6 in the cell populations (Fig. 5c).

Similar to CD133, nestin was observed in all examined cell lines, and both the percentage and the intensity of immunostaining of Nes+ cells varied among individual cell lines (Table 3, Fig. 3). Using immunoblotting, we confirmed that nestin is present in all five cell lines, and the specific bands detected were $300 \mathrm{kDa}, 270 \mathrm{kDa}$ and $100 \mathrm{kDa}$ (Fig. 4b). Nevertheless, Nes+ cells only represent minor subpopulations, and the level of immunostaining was lower, compared to CD133+ cells (Table 3). Additionally, all Nes+ cells expressed CD133, but not all CD133+ cells expressed nestin (Fig. 3c and d). In contrast to the changes in CD133 expression mentioned above, expression of 

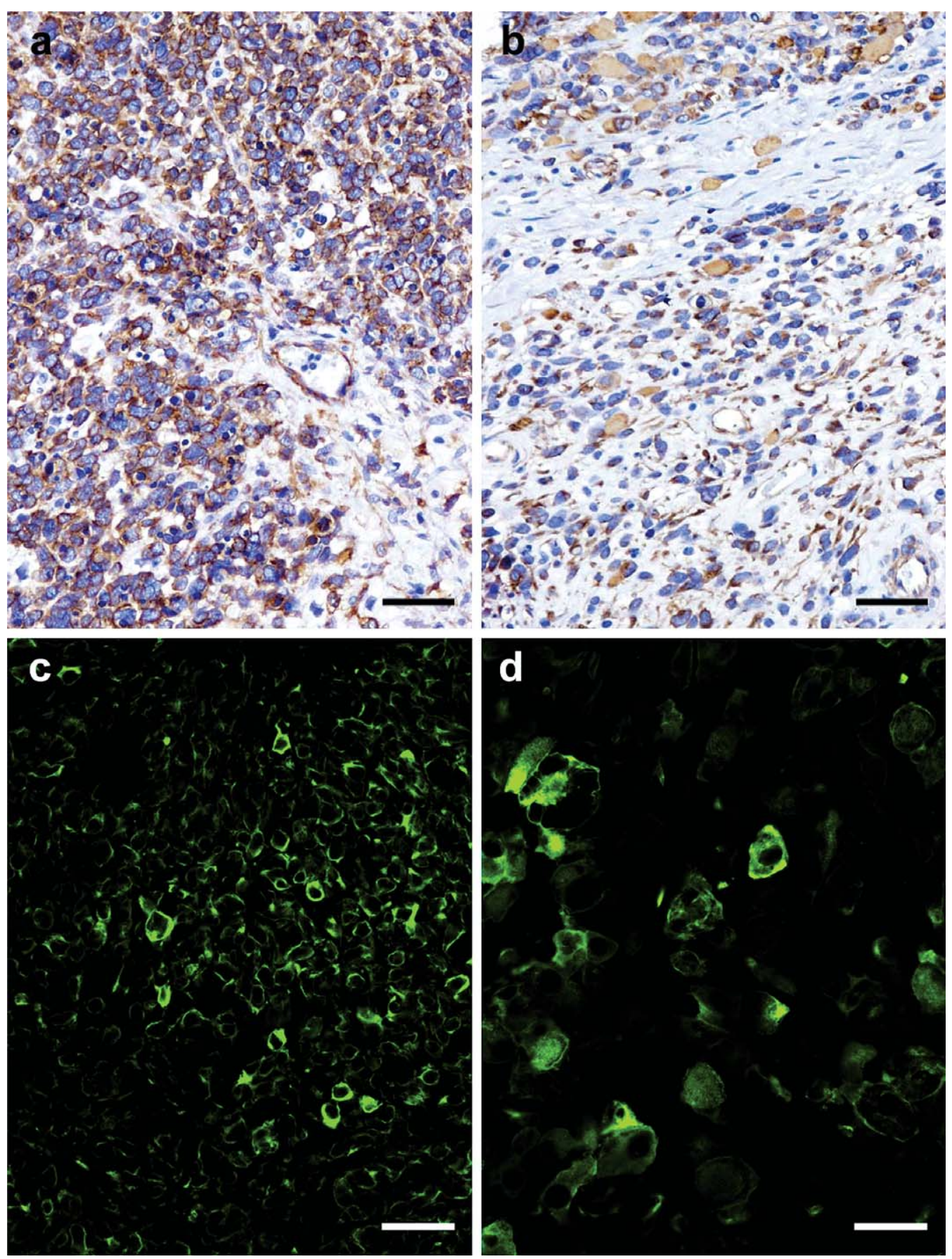

Fig. 2. Immunohistochemical and immunofluorescence analysis of nestin expression in rhabdomyosarcomas tissues. Strong, diffuse cytoplasmic positivity in the majority of tumor cells with an internal positive control of Nes+ endothelial cells; sample 8 (a). Medium cytoplasmic nestin immunostaining in a subset of dispersed tumor cells; sample 7 (b). Nestin expression in a significant proportion of tumor cells; sample 8 (c). Nestin expression in individual tumor cells; sample 4 (d). Immunohistochemistry with Gill's hematoxylin counterstain (a, b); indirect immunofluorescence using FITC-labeled secondary antibody (c, d). Bars, $100 \mu \mathrm{m}$ (a, b, c), $50 \mu \mathrm{m}$ (d). 
Table 3

Expression of CD133 and nestin in the rhabdomyosarcoma cell lines

\begin{tabular}{lcccccc}
\hline Cell line & Tumor type & \multicolumn{2}{c}{ CD133 } & & \multicolumn{2}{c}{ Nestin } \\
& & \% TC & IR TC & & $\%$ TC & IR TC \\
\hline NSTS-08 & A & +++ & ++ & + & + \\
NSTS-09 & A & $++(+)$ & +++ & $+(+)$ & ++ \\
NSTS-10 & A & +++ & ++ & & $+(+)$ & ++ \\
NSTS-11 & E & ++ & $++/+++$ & $+(+)$ & + \\
NSTS-12 & E & +++ & $++/+++$ & & $(+)$ & + \\
\hline
\end{tabular}

Notes: Expression of CD133 and nestin in cell lines was examined using indirect immunofluorescence method. \% TC, percentage of CD133/nestin positive tumor cells: $(+), \sim 1 \% ;+, 1-10 \%$; $+(+)$, $\sim 10 \% ;++, 10-50 \% ;++(+), \sim 50 \% ;+++,>50 \%$. IR TC, intensity of immunostaining (immunoreactivity) in tumor cells: + , weak; ++ , medium; +++, strong. Tumor type: A, rhabdomyosarcoma, alveolar type; E, rhabdomyosarcoma, embryonal type.

nestin in cell populations was not altered during the cultivation.

\subsection{Detection of CD133 and nestin in different samples from the same patient}

As mentioned in Table 1, four FFPE tissue samples and two derived cell lines were obtained from the same patient suffering from rhabdomyosarcoma during the progression of the disease. This situation gave us the unique opportunity to analyze possible changes in CD133 and nestin expression in tumor tissue of the same patient in relation to the clinical course of the disease and to the applied therapy.

A 21-year-old woman was diagnosed with alveolar rhabdomyosarcoma of the left forearm and regional axillary lymph nodes, IRS stage III (tumor sample No. 7a, NSTS-08 cell line). She was treated according to protocol "EpSSG RMS 2005" very high risk arm with systemic chemotherapy of ifosfamide, vincristine, actinomycin D, and doxorubicin. After three initial courses, the patient was re-evaluated by PET and MRI imaging and determined to have a stable disease response. The tumor was inoperable without mutilating surgery, but amputation was rejected by the patient. Locoregional marginal surgery was performed, and she achieved 1 st complete remission (tumor sample No. 7b, NSTS-10 cell line). Despite a second line of chemotherapy with irinotecan and vincristine, radiotherapy and metronomic antiangiogenic therapy, she relapsed in the regional lymph nodes on her shoulder (tumor sample No. 7c); her event-free survival was 13 months. Salvage chemotherapy with topote- can and carboplatin was administered, but again, stable disease was found upon imaging. Following resection (tumor sample No. 7d) and radiotherapy, she achieved a 2nd complete remission. Several months later, she was diagnosed with a 3rd locoregional relapse on her shoulder; her event-free survival was 7 months. After a discussion with the patient, a dendritic cell vaccine against PAX3/FKHR protein was prepared. Meanwhile, concomitant chemotherapy with irinotecan, vincristine, and temodal, and radiotherapy were administered. Amputation was not accepted by the patient, despite a poor prognosis for survival. Unfortunately, the patient was diagnosed with metastatic relapse in the bones and bone marrow nine months later. As an experimental approach, a dendritic cell vaccine was applied together with palliative radiotherapy to a pathologic fracture of the vertebra. Currently, the experimental treatment with vincristine, cyclophosphamide, bevacizumab, sirolimus and valproate was administered. The overall survival of this patient is 39 months, and her prognosis remains very poor; such patients usually survive no more than three years after diagnosis.

Analysis of CD133 and nestin expression in all four tumor samples taken from this patient at various stages of the disease (see above) showed a sporadic occurrence of CD133+ cells with relatively strong immunoreactivity and a high proportion of Nes+ cells with medium to weak immunoreactivity. The frequency both of CD133+ and Nes+ cells did not change significantly during the course of the disease (Table 2).

The cell lines derived from the primary tumor (NSTS-08 cell line) and from the tumor tissue after the first chemotherapy treatment (NSTS-10 cell line) also showed the very same frequency of CD133+ and/or Nes+ cells; and the immunoreactivity for both of these markers was stable in both of these cell lines (Table 3 ).

\subsection{Expression of stem cell markers in rhabdomyosarcoma cell lines}

To confirm the presence of cells with stem cell related markers in rhabdomyosarcoma cell lines, we employed RT-PCR for detection of Oct3/4 (POU5F1) and nucleostemin (GNL3) that are considered to be markers of the embryonic stem cells. All five cell lines were identified as positive for both of these markers (Fig. 6); however, their expression partly differed among cell lines: a strong expression of Oct $3 / 4$ was 

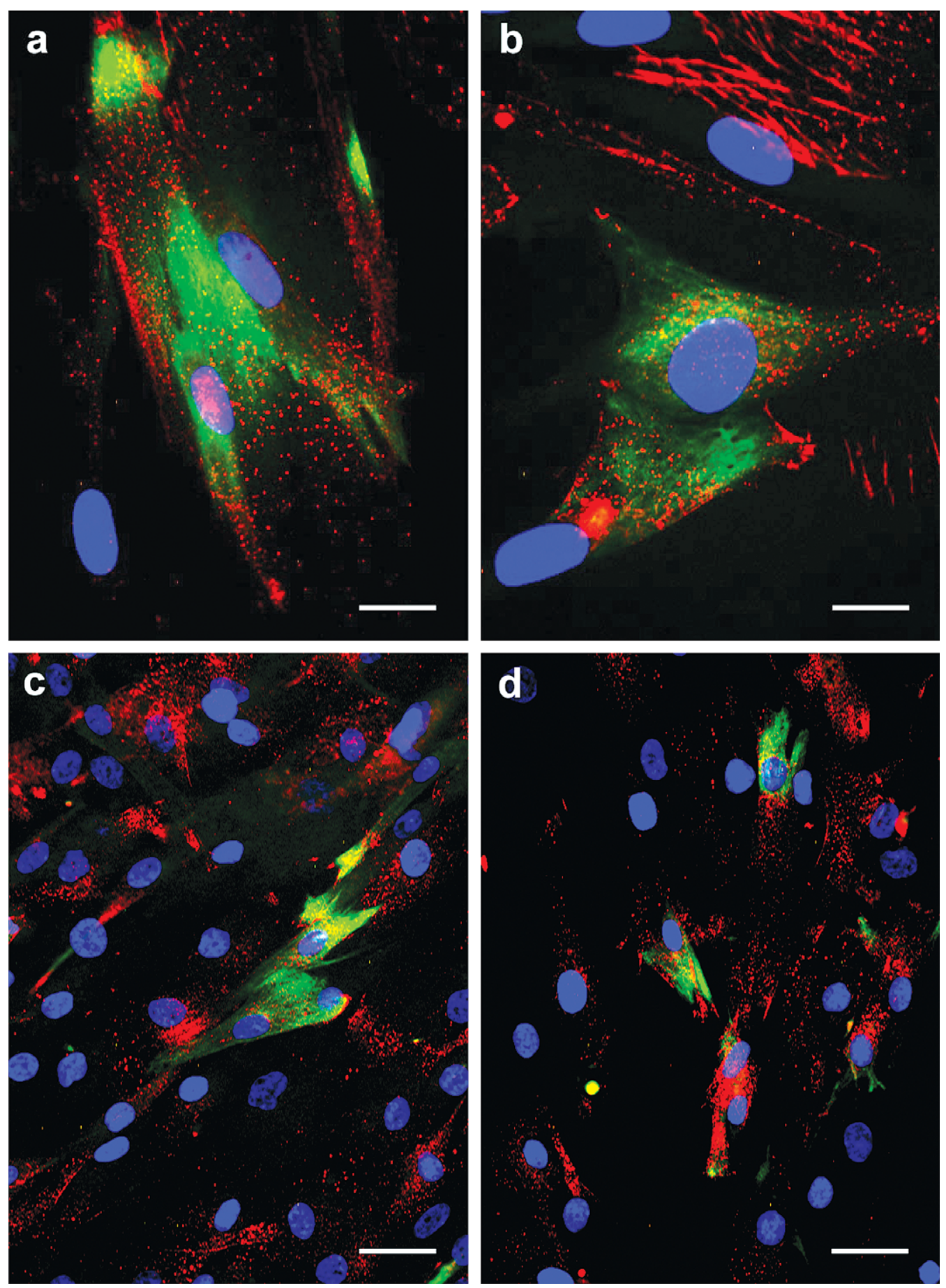

Fig. 3. Expression of CD133 and nestin in rhabdomyosarcoma cell lines. Representative double labeling for CD133 and nestin in NSTS-9 (a, b) and NSTS-8 (c, d) rhabdomyosarcoma cell lines. CD133 showed predominantly membranous positivity, visible as a dotted CD133 signal (red) on the cell surface (a-d). Invaginations of plasma membrane accumulating CD133 signals (red) led to the stripped pattern in a small subset of cells (b). CD133 (red) and nestin (green) stained by indirect immunofluorescence using TRITC-labeled secondary antibody and FITC-labeled secondary antibody, respectively; counterstaining with DAPI. Bars, $25 \mu \mathrm{m}(\mathrm{a}, \mathrm{b}), 50 \mu \mathrm{m}(\mathrm{c}, \mathrm{d})$. 

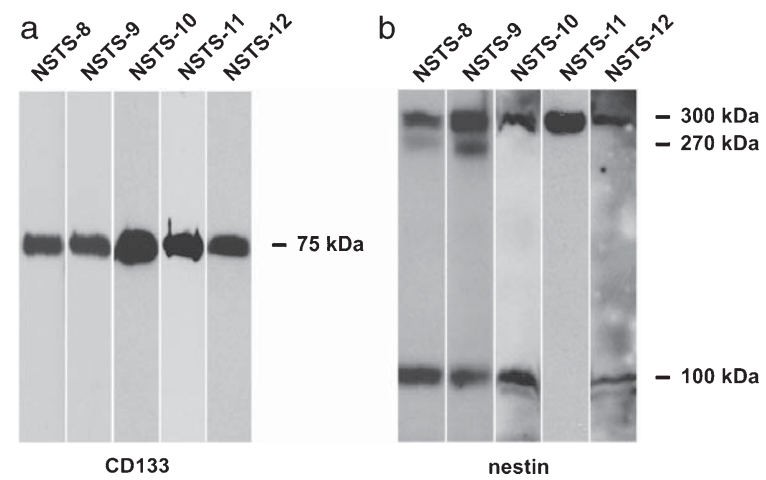

Fig. 4. Immunoblot analysis of the CD133 and nestin expression in rhabdomyosarcoma cell lines. Analysis of the CD133 expression in all five rhabdomyosarcoma cell lines (a). Analysis of the nestin expression in all five rhabdomyosarcoma cell lines (b).

identified in NSTS-8, NSTS-9, and NSTS-12 cell lines, a medium in NSTS-10 and a low expression in NSTS11 , while a medium expression of nucleostemin was detected in all cell lines with exception of NSTS-10 that showed only low level of nucleostemin expression (Fig. 6).

\subsection{Functional assays using NSTS-11 cells}

To confirm the presence of cells with cancer stem cell phenotype in our cell lines, we performed preliminary functional assays on NSTS-11 cell line. Clonogenicity in vitro assay showed that 5 to $10 \%$ of isolated cells were able under standard in vitro conditions to form colonies containing more than 50 cells (Fig.7).

Furthermore, the tumorigenicity in vivo assay clearly confirmed the ability of NSTS-11 cells to originate xenograft tumors in NOD/SCID mice (Fig. 8). All three mice injected with NSTS-11 cell suspensions developed subcutaneous tumors in the same positions (Fig. 8a-c) within 12 weeks after injection. The diameter of all three tumors was about $10 \mathrm{~mm}$ (Fig. 8 d-f). Histological examination of all these xenograft tumors showed neoplastic highly mitotically active proliferation of undifferentiated dominantly spindleshaped cells admixed with number of round, strapor tadpole-shaped eosinophilic rhabdomyoblasts in a partially myxoid stroma (Fig. 8g-i). Moreover, the cross-striation of several cells has been displayed in all examined tumor samples. Histopathological findings correlate with the diagnosis of embryonal rhabdomyosarcoma. Myogenic differentiation was additionally proved immunohistochemically in all three xenograft tumors (Table 4).

\section{Discussion}

The focus of our study was on the detection of CD133 and nestin in rhabdomyosarcoma cells. Ten samples of rhabdomyosarcoma tumor tissue and five cell lines derived from these tumors were examined using immunodetection methods; RT-PCR and functional assays were also employed to analyze the cell lines. Expression of both CD133 and nestin was microscopically determined in all tissue samples and cell lines; in the cell lines, these finding were confirmed by immunoblotting. Cells with distinct membranous positivity for CD133 occurred only sporadically in tumor tissues, although the proportion of Nes+ cells was markedly higher in the same tissues. In contrast, all five rhabdomyosarcoma cell lines showed an increased frequency of CD133+ cells, only some of which were concurrently Nes+. Above all, our research provides the first evidence of CD133 expression in rhabdomyosarcomas.

CD133 glycoprotein is considered to be a marker of the CSC phenotype in many kinds of tumors, usually in combination with other cell surface or intracellular molecules; for example: with nestin in CNS tumors [9, 24, 33, 34, 47], with CD44 in hepatocellular carcinomas [20,48] and in colon carcinomas [15], with CD44 and $\alpha_{1} \beta_{2}$ hi in prostate carcinomas [4], and with ABCG2 in pancreatic adenocarcinomas [25] and in osteosarcomas [10]. Nevertheless, expression of CD133 alone was also reported as a CSC phenotype in colon carcinomas [28], in non-small-cell lung carcinomas $[2,38]$, in ovarian carcinomas [8] and in endometrial carcinomas [30].

The detection of cells showing membranous positivity for CD133 that were only sporadically dispersed in rhabdomyosarcoma tumor tissues suggests that these cells may act as CSCs/TICs in this tumor type. In cell lines derived from the same tumors, we noted a markedly higher proportion of CD133+ cells; this difference may be explained by clonal selection for this phenotype under in vitro conditions. Since our results are the first evidence of CD133 expression in rhabdomyosarcoma cells, we verified these findings by immunoblotting cell lysates from five rhabdomyosarcoma cell lines examined in this study. Immunoblot results undoubtedly showed the CD133 expression; 
a
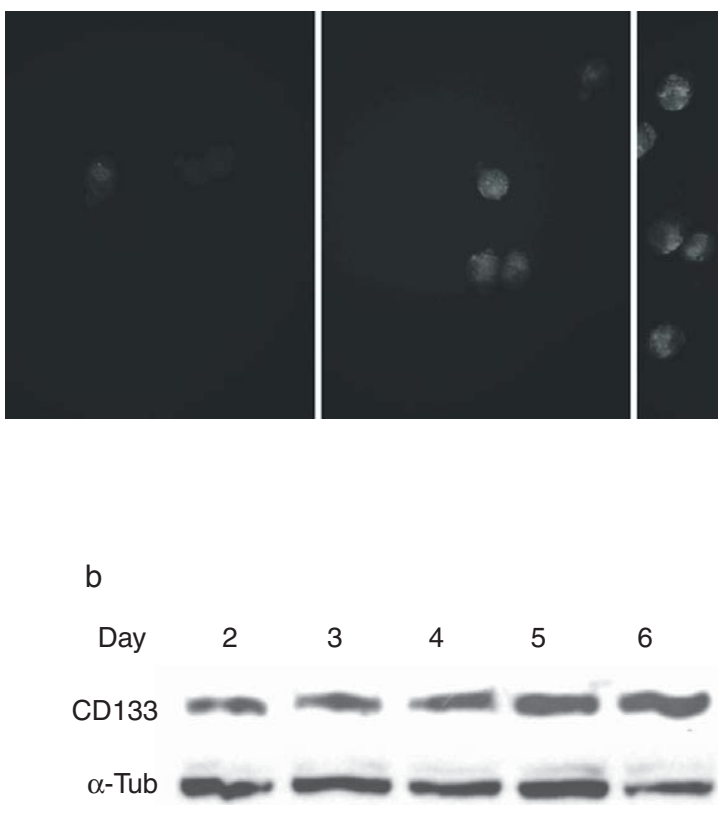

Day 4

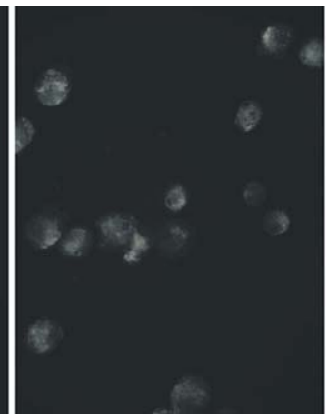

C $\quad 0.050$

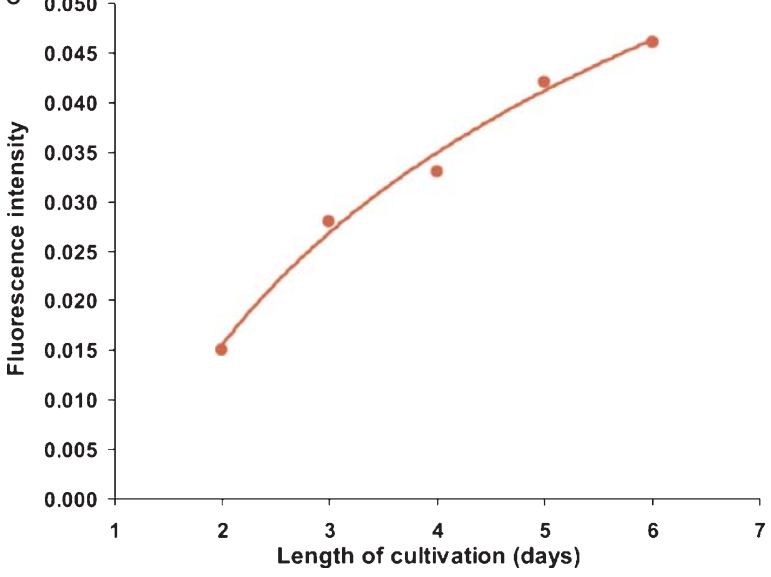

Fig. 5. CD133 expression changes in the rhabdomyosarcoma cell line NSTS-11 during a six-day cultivation. Cell suspensions were stained against CD133 (green) by indirect immunofluorescence using a FITC-labeled secondary antibody and were simultaneously analyzed using a fluorescence microscope; bar $50 \mu \mathrm{m}$ (a) and by flow-cytometry (c). Fluorescence intensity (FI) is calculated as a quotient of difference; FITC-A $\log$ CD133 median fluorescence intensity (MFI) with FITC-A $\log$ Iso MFI, and FSC-A where: FITC-A $\log$ CD133 is calculated as the mean $(n=2)$ of medians FITC-A $\log$ in samples immunostained with rabbit polyclonal anti-CD133 primary antibody, FITC-A $l o g$ Iso is calculated as a mean $(n=2)$ of medians FITC-A log in samples immunostained with rabbit polyclonal isotype control, FSC-A is calculated as a mean $(n=4)$ of medians FSC-A above mentioned all samples. FI = (FITC-A $\log _{\text {CD133 }}$-FITC-A $\left.\log _{\text {Iso }}\right) /$ FSC-A. Immunoblot analysis of the CD133 expression changes during a six-day cultivation (b). Alpha-tubulin ( $\alpha$-Tub) served as a loading control.

a specific $75-\mathrm{kDa}$ band was detected in all cell lines, suggesting the presence of a truncated form of CD133 that was described by two independent studies $[26,41]$.

During the in vitro experiments, we also noted increased fluorescence in individual CD133+ cells in relation to a prolonged cultivation time. For this reason, we measured the cell populations seeded at the same concentrations and at the same time. By flow cytometry, we confirmed a substantial increase in fluorescence of the whole cell population during a six-day cultivation; non-specific fluorescence and the average size of individual cells was taken into account in this experiment. In parallel, we used a fluorescence microscope to confirm the increase of CD133 labeling in individ-

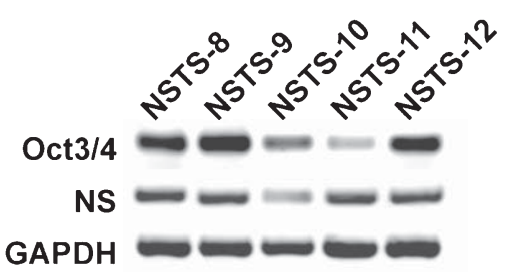

Fig. 6. RT-PCR analysis of stemness markers in rhabdomyosarcoma cell lines. Expression of Oct3/4 and nucleostemin was analyzed in all five of these cell lines; GAPDH served as a control.

ual cells. Moreover, these microscopic observations suggest not only membranous, but also cytoplasmic localization of CD133 molecules. These findings are in agreement with another study on osteosarcoma 

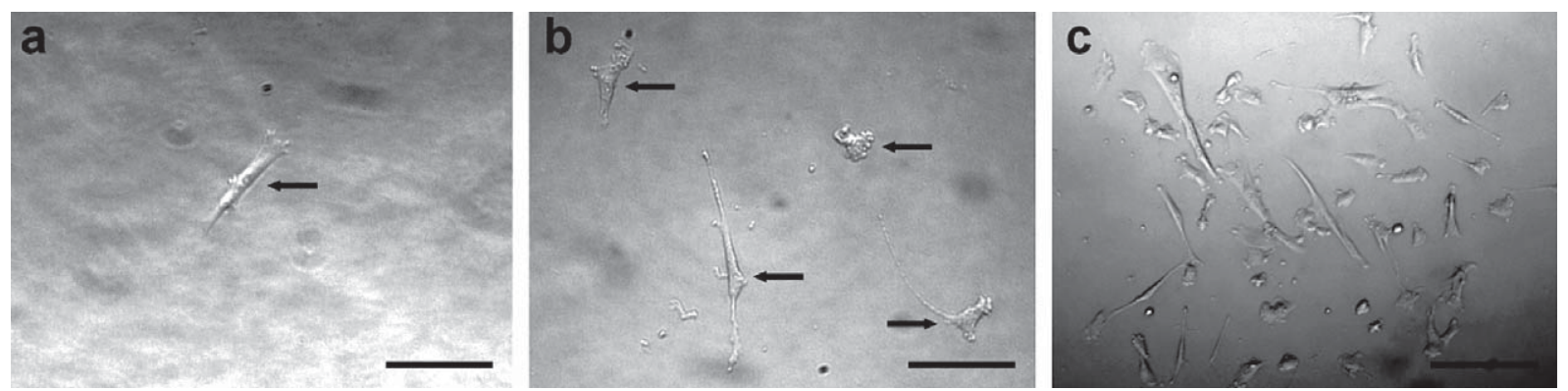

Fig. 7. Clonogenicity assay in vitro using NSTS-11 cell line. During two weeks of cultivation, single isolated cells (7a) were able to proliferate (7b) and to form colonies containing more than 50 cells (7c). Bars, $100 \mu \mathrm{m}(\mathrm{a}, \mathrm{b}), 200 \mu \mathrm{m}$ (c).
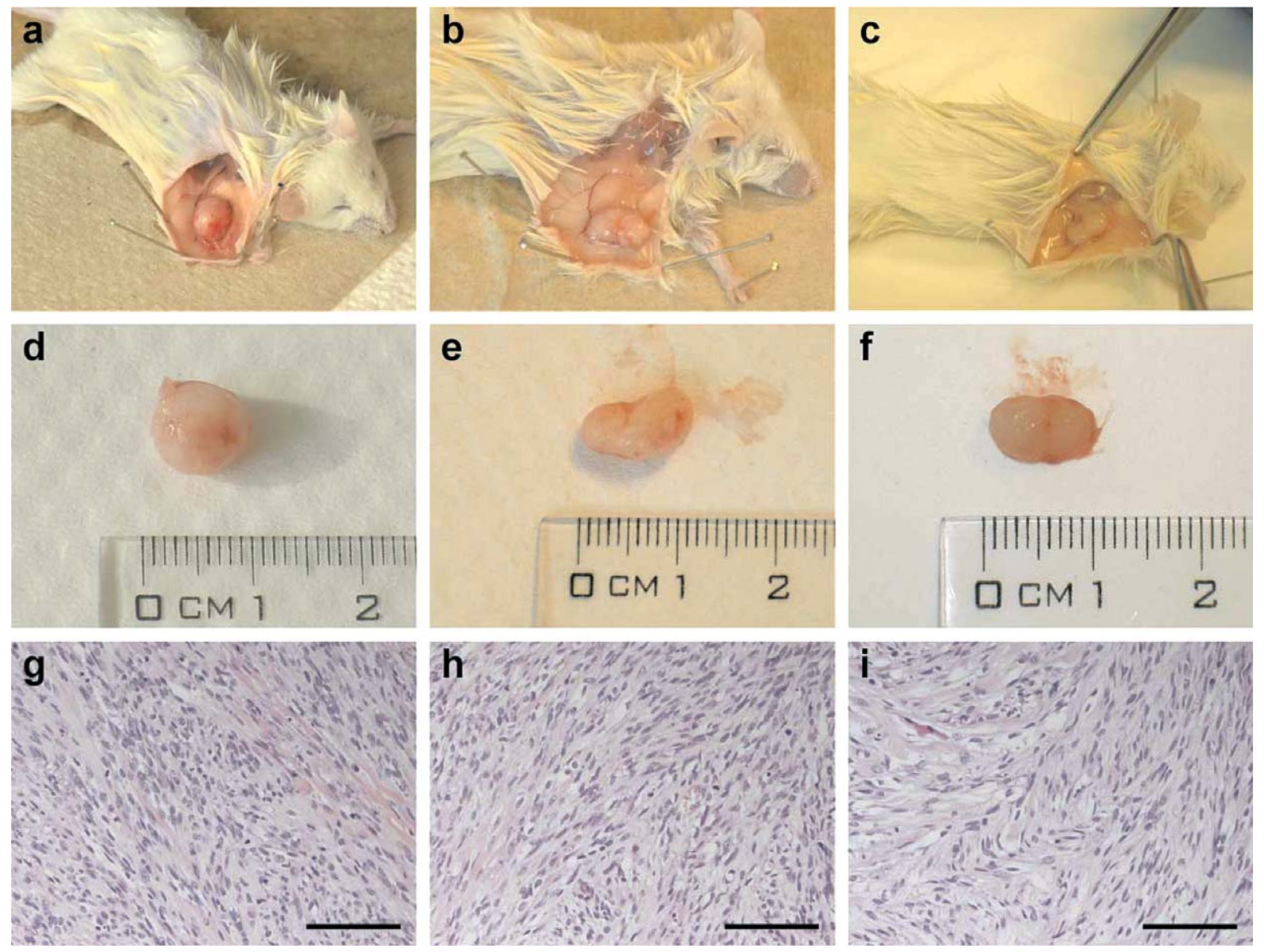

Fig. 8. Tumorigenicity in vivo assay using NSTS-11 cell line. Subcutaneous xenograft tumors in NOD/SCID mice at 81-84 days after injection of NSTS-11 cells ( $8 \mathrm{a}-\mathrm{c})$. Size of all three tumors was about $10 \mathrm{~mm}$ in diameter $(8 \mathrm{~d}-\mathrm{f})$. Histological examination of these tumors showed a pattern corresponding to the diagnosis of embryonal rhabdomyosarcoma; bars, $200 \mu \mathrm{m}(8 \mathrm{~g}-\mathrm{i})$.

cells, in which the deposition of CD133 into cytoplasmic vesicles was visualized by confocal microscopy [39].
Based on our previous study of osteosarcoma cell lines, in which the co-expression of CD133 and nestin was described in sarcomas for the first time [42], we 
Table 4

Immunohistochemical analysis of NSTS-11 xenograft tumors in mice

\begin{tabular}{lccccc}
\hline Tumor & Myoglobin & Desmin & Muscle actin & Nestin & CD133 \\
\hline M3A138 & ++ & ++ & ++ & +++ & \pm \\
M3B138 & + & ++ & ++ & +++ & \pm \\
M3C138 & + & ++ & ++ & +++ & \pm \\
\hline
\end{tabular}

Notes: Expression of myogenic differentiation markers (myoglobin, desmin, muscle actin), CD133 and nestin was examined on formalinfixed, paraffin embedded tissue samples of xenograft tumors using immunohistochemistry (IHC). Evaluation of IHC: percentage of positive tumor cells $( \pm,<2 \% ;+, 2-10 \%$; ++, 11-50\%; +++, $51-100 \%)$.

also examined the rhabdomyosarcoma samples and derived cell lines for the detection of this intermediate filament protein. Although nestin expression was reported in many tumor types including sarcomas [18], and nestin was originally described in rhabdomyosarcoma cells twelve years ago [17], there is no published work describing a possible co-expression of nestin and CD133 in rhabdomyosarcomas.

Our microscopy results confirmed that nestin is expressed in all our rhabdomyosarcoma samples as well as in all the derived rhabdomyosarcoma cell lines. Immunoblotting was employed to verify nestin expression in the examined cell lines; $300 \mathrm{kDa}, 270 \mathrm{kDa}$ and $100 \mathrm{kDa}$ specific bands were detected in all of them. The $300 \mathrm{kDa}$ and $270 \mathrm{kDa}$ bands correspond to posttranslationally-modified forms of nestin; the $100 \mathrm{kDa}$ band is probably nestin that has been cleaved by lysate cryoconservation, as reported by the antibody manufacturer.

More interestingly, the expression pattern of nestin was inversely correlated to that of CD133; we detected a relatively high proportion of Nes+ cells in tumor tissues together with a sporadic occurrence of CD133+ cells, whereas CD133+ cells predominated the cell populations of all examined cell lines, including Nes+ cells, under in vitro conditions. Furthermore, all Nes+ cells in the cultures showed positivity for CD133 simultaneously; i.e. their phenotype was CD133+/Nes+, while CD133-/Nes+ cells were never been detected in the cell cultures.

Taken together, the sporadic occurrence of CD133+ cells (with distinct membranous positivity) in tumor tissues and a minor proportion of CD133+/Nes+ in cell cultures suggest that these cancer cells with expression of stem cell related markers may represent a CSCs/TICs phenotype in rhabdomyosarcomas. Posi- tivity of all five examined cell lines for Oct3/4 and nucleostemin that are required for maintaining stem cell state [10] is in accordance with this idea. The hypothesis on CSCs/TICs phenotype is also partially supported by CD133 and nestin detection in different tumor samples taken from the same patient at various stages of the disease. The relatively stable frequency of CD133+ cells in tumor samples during cancer progression in this patient may indicate a resistance of these cells to the applied chemotherapy. Similarly, the presence of these cells in sample No.3 that was taken after neoadjuvant chemotherapy also suggests their CSCs/TICs phenotype.

Moreover, results of preliminary functional assays using our rhabdomyosarcoma cell lines also suggest the presence of a CSCs/TICs fraction in these cell lines. Nevertheless, further detailed functional studies of CD133+/Nes+ rhabdomyosarcoma cells are required to confirm their possible CSCs/TICs phenotype.

To summarize, the most important result of our study is the first evidence of CD133 expression in rhabdomyosarcomas and the corresponding rhabdomyosarcoma cell lines. Using immunodetection methods, we confirmed the expression of CD133 and nestin in all examined tumor samples and in all cell lines derived from them. The low incidence of CD133+ cells in tumor tissues and of CD133+/Nes+ cells in cultures as well as results of preliminary functional assays suggest a possible stem-like phenotype of cells showing co-expression of these markers. We also showed increasing expression of CD133 in rhabdomyosarcoma cells and probable accumulation of this glycoprotein in cytoplasmic vesicles during cultivation. Our results represent the first important step toward the forthcoming studies on CSCs/TICs detection in rhabdomyosarcomas.

\section{Acknowledgments}

The authors would like to thank Mrs. Hana Rychtecka, Mrs. Marcela Vesela, Mrs. Johana Maresova and Dr. Jan Verner for their skillful technical assistance. We are grateful to Dr. Rudolf Nenutil for providing tumor samples from the files of the Department of Oncological and Experimental Pathology, Masaryk Memorial Cancer Institute (Brno, Czech Republic). We also thank Professor Roman Hajek for providing the flow cytometry facilities and Dr. Ivana Buresova for her assistance in perform- 
ing flow cytometry. This study was supported by grants VZ MSM 0021622415, VZ MSM 0021622430, IGA MZCR NR/9125-4 2006, MUNI/A/0091/2009, MUNI/A/1012/2009, MUNI/A/0950/2010 and GACR 204/08/H054.

\section{References}

[1] F.G. Barr, J. Chatten, C.M. D'Cruz, A.E. Wilson, L.E. Nauta, L.M. Nycum, J.A. Biegel and R.B. Womer, Molecular assays for chromosomal translocations in the diagnosis of pediatric soft tissue sarcomas, JAMA 273 (1995), 553-557.

[2] G. Bertolini, L. Roz, P. Perego, M. Tortoreto, E. Fontanella, L. Gatti, G. Pratesi, A. Fabbri, F. Andriani, S. Tinelli, E. Roz, R. Caserini, S. Lo Vullo, T. Camerini, L. Mariani, D. Delia, E. Calabrò, U. Pastorino and G. Sozzi, Highly tumorigenic lung cancer CD133+ cells display stem-like features and are spared by cisplatin treatment, Proc Natl Acad Sci USA 106 (2009), 16281-16286.

[3] S. Bruno, B. Bussolati, C. Grange, F. Collino, M.E. Graziano, U. Ferrando and G. Camussi, CD133+ renal progenitor cells contribute to tumor angiogenesis, Am J Pathol 169 (2006), 2223-2235.

[4] A.T. Collins, P.A. Berry, C. Hyde, M.J. Stower and N.J. Maitland, Prospective identification of tumorigenic prostate cancer stem cells, Cancer Res 65 (2005), 10946-10951.

[5] D. Corbeil, K. Röper, C.A. Fargeas, A. Joester and W.B. Huttner, Prominin: A story of cholesterol, plasma membrane protrusions and human pathology, Traffic 2 (2001), 82-91.

[6] D. Corbeil, K. Röper, A. Hellwig, M. Tavian, S. Miraglia, S.M. Watt, P.J. Simmons, B. Peault, D.W. Buck and W.B. Huttner, The human AC133 hematopoietic stem cell antigen is also expressed in epithelial cells and targeted to plasma membrane protrusions, J Biol Chem 275 (2000), 5512-5520.

[7] C.V. Cox, P. Diamanti, R.S. Evely, P.R. Kearns and A. Blair, Expression of CD133 on leukemia-initiating cells in childhood ALL, Blood 113 (2009), 3287-3296.

[8] M.D. Curley, V.A. Therrien, C.L. Cummings, P.A. Sergent, C.R. Koulouris, A.M. Friel, D.J. Roberts, M.V. Seiden, D.T. Scadden, B.R. Rueda and R. Foster, CD133 expression defines a tumor initiating cell population in primary human ovarian cancer, Stem Cells 27 (2009), 2875-2883.

[9] P. Dell'Albani, Stem cell markers in gliomas, Neurochem Res 33 (2008), 2407-2415.

[10] R. Di Fiore, A. Santulli, R.D. Ferrante, M. Giuliano, A. De Blasio, C. Messina, G. Pirozzi, V. Tirino, G. Tesoriere and R. Vento, Identification and expansion of human osteosarcomacancer-stem cells by long-term 3-aminobenzamide treatment, J Cell Physiol 219 (2009), 301-313.

[11] A. Eramo, F. Lotti, G. Sette, E. Pilozzi, M. Biffoni, A. Di Virgilio, C. Conticello, L. Ruco, C. Peschle and R. De Maria, Identification and expansion of the tumorigenic lung cancer stem cell population, Cell Death Differ 15 (2008), 504-514.

[12] C.A. Fargeas, W.B. Huttner and D. Corbeil, Nomenclature of prominin-1 (CD133) splice variants - an update, Tissue Antigens 69 (2007), 602-606.

[13] C.A. Fargeas, A. Joester, E. Missol-Kolka, A. Hellwig, W.B. Huttner and D. Corbeil, Identification of novel Prominin-
1/CD133 splice variants with alternative C-termini and their expression in epididymis and testis, J Cell Sci 117 (2004), 4301-4311.

[14] G. Ferrandina, G. Bonanno, L. Pierelli, A. Perillo, A. Procoli, A. Mariotti, M. Corallo, E. Martinelli, S. Rutella, A. Paglia, G. Zannoni, S. Mancuso and G. Scambia, Expression of CD1331 and CD133-2 in ovarian cancer, Int J Gynecol Cancer 18 (2008), 506-514.

[15] N. Haraguchi, M. Ohkuma, H. Sakashita, S. Matsuzaki, F. Tanaka, K. Mimori, Y. Kamohara, H. Inoue and M. Mori, CD133+ CD44+ population efficiently enriches colon cancer initiating cells, Ann Surg Oncol 15 (2008), 2927-2933.

[16] H. Immervoll, D. Hoem, P.O. Sakariassen, O.J. Steffensen and A. Molven, Expression of the "stem cell marker" CD133 in pancreas and pancreatic ductal adenocarcinomas, BMC Cancer 8 (2008), 48.

[17] M. Kobayashi, G. Sjöberg, S. Söderhäll, U. Lendahl, B. Sandstedt and T. Sejersen, Pediatric rhabdomyosarcomas express the intermediate filament nestin, Pediatr Res 43 (1998), 386-392.

[18] O. Krupkova, T. Loja, I. Zambo and R. Veselska, Nestin expression in human tumors and tumor cell lines, Neoplasma 57 (2010), 291-298.

[19] G. Liu, X. Yuan, Z. Zeng, P. Tunici, H. Ng, I.R. Abdulkadir, L. Lu, D. Irvin, K.L. Black and J.S. Yu, Analysis of gene expression and chemoresistance of CD133+ cancer stem cells in glioblastoma, Mol Cancer 5 (2006), 67.

[20] S. Ma, K.W. Chan, L. Hu, T.K. Lee, J.Y. Wo, I.O. Ng, B.J. Zheng and X.Y. Guan, Identification and characterization of tumorigenic liver cancer stem/progenitor cells, Gastroenterology 132 (2007), 2542-2556.

[21] S. Miraglia, W. Godfrey, A.H. Yin, K. Atkins, R. Warnke, J.T. Holden, R.A. Bray, E.K. Waller and D.W. Buck, A novel five-transmembrane hematopoietic stem cell antigen: Isolation, characterization, and molecular cloning, Blood 90 (1997), 5013-5021.

[22] E. Monzani, F. Facchetti, E. Galmozzi, E. Corsini, A. Benetti, C. Cavazzin, A. Gritti, A. Piccinini, D. Porro, M. Santinami, G. Invernici, E. Parati, G. Alessandri and C.A. La Porta, Melanoma contains CD133 and ABCG2 positive cells with enhanced tumourigenic potential, Eur J Cancer 43 (2007), 935-936.

[23] Y.R. Na, S.H. Seok, D.J. Kim, J.H. Han, T.H. Kim, H. Jung and J.H. Park, Zebrafish embryo extracts promote sphere-forming abilities of human melanoma cell line, Cancer Sci 100 (2009), 1429-1433.

[24] J. Neuzil, M. Stantic, R. Zobalova, J. Chladova, X. Wang, L. Prochazka, L. Dong, L. Andera and S.J. Ralph, Tumourinitiating cells vs. cancer 'stem' cells and CD133: What's in the name? Biochem Biophys Res Commun 355 (2007), 855859.

[25] M. Olempska, P.A. Eisenach, O. Ammerpohl, H. Ungefroren, F. Fendrich and H. Kalthoff, Detection of tumor stem cell markers in pancreatic carcinoma cell lines, Hepatobiliary Pancreat Dis Int 6 (2007), 92-97.

[26] T.L. Osmond, K.W. Broadley and M.J. McConnell, Glioblastoma cells negative for the anti-CD133 antibody AC133 express a truncated variant of the CD133 protein, Int J Mol Med 25 (2010), 883-888.

[27] G.J. Pilkington, Cancer stem cells in the mammalian central nervous system, Cell Prolif 38 (2005), 423-433. 
[28] L. Ricci-Vitiani, D.G. Lombardi, E. Pilozzi, M. Biffoni, M. Todaro, C. Peschle and R. De Maria, Identification and expansion of human colon cancer-initiating cells, Nature 445 (2007), 111-115.

[29] G.D. Richardson, C.N. Robson, S.H. Lang, D.E. Neal, N.J. Maitland and A.T. Collins, CD133 a novel marker for human prostatic epithelial stem cells, J Cell Sci 117 (2004), 3539-3545.

[30] S. Rutella, G. Bonanno, A. Procoli, A. Mariotti, M. Corallo, M.G. Prisco, A. Eramo, C. Napoletano, D. Gallo, A. Perillo, M. Nuti, L. Pierelli, U. Testa, G. Scambia and G. Ferrandina, Cells with characteristics of cancer stem/progenitor cells express the CD133 antigen in human endometrial tumors, Clin Cancer Res 15 (2009), 4299-4311.

[31] C. Sagrinati, G.S. Netti, B. Mazzinghi, E. Lazzeri, F. Liotta, F. Frosali, E. Ronconi, C. Meini, M. Gacci, R. Squecco, M. Carini, L. Gesualdo, F. Francini, E. Maggi, F. Annunziato, L. Lasagni, M. Serio, S. Romagnani and P. Romagnani, Isolation and characterization of multipotent progenitor cells from the Bowman's capsule of adult human kidneys, J Am Soc Nephrol 17 (2006), 2443-2456.

[32] S.V. Shmelkov, R. St Clair, D. Lyden and S. Rafii, AC133/ CD133/Prominin-1, Int J Biochem Cell Biol 37 (2005), 715-719.

[33] S.K. Singh, I.D. Clarke, M. Terasaki, V.E. Bonn, C. Hawkins, J. Squire and P.B. Dirks, Identification of a cancer stem cell in human brain tumors, Cancer Res 63 (2003), 5821-5828.

[34] S.K. Singh, C. Hawkins, I.D. Clarke, J.A. Squire, J. Bayani, T. Hide, R.M. Henkelman, M.D. Cusimano and P.B. Dirks, Identification of human brain tumour initiating cells, Nature 432 (2004), 396-401.

[35] A. Suetsugu, M. Nagaki, H. Aoki, T. Motohashi, T. Kunisada and H. Moriwaki, Characterization of CD133+ hepatocellular carcinoma cells as cancer stem/progenitor cells, Biochem Biophys Res Commun 351 (2006), 820-824.

[36] J. Terry and T. Nielsen, Expression of CD133 in synovial sarcoma, Appl Immunohistochem Mol Morphol 18 (2010), $159-165$.

[37] B. Thomson, D. Hawkins, J. Felgenhauer and J.P. Radich, RT-PCR evaluation of peripheral blood, bone marrow and peripheral blood stem cells in children and adolescents undergoing VACIME chemotherapy for Ewing's sarcoma and alveolar rhabdomyosarcoma, Bone Marrow Transplant 24 (1999), 527-533.

[38] V. Tirino, R. Camerlingo, R. Franco, D. Malanga, A. La Rocca, G. Viglietto, G. Rocco and G. Pirozzi, The role of CD133 in the identification and characterisation of tumour-initiating cells in non-small-cell lung cancer, Eur J Cardiothorac Surg 36 (2009), 446-453.

[39] V. Tirino, V. Desiderio, R. d'Aquino, F. De Francesco, G. Pirozzi, A. Graziano, U. Galderisi, C. Cavaliere, A. De Rosa, G. Papaccio and A. Giordano, Detection and characterization of CD133+ cancer stem cells in human solid tumours, PLoS One 3 (2008), e3469.

[40] N. Uchida, D.W. Buck, D. He, M.J. Reitsma, M. Masek, T.V. Phan, A.S. Tsukamoto, F.H. Gage and I.L. Weissman, Direct isolation of human central nervous system stem cells, Proc Natl Acad Sci USA 97 (2000), 14720-14725.

[41] D.J. Vander Griend, W.L. Karthaus, S. Dalrymple, A. Meeker, A.M. DeMarzo and J.T. Isaacs, The role of CD133 in normal human prostate stem cells and malignant cancer-initiating cells, Cancer Res 68 (2008), 9703-9711.

[42] R. Veselska, M. Hermanova, T. Loja, P. Chlapek, I. Zambo, K. Vesely, K. Zitterbart and J. Sterba, Nestin expression in osteosarcomas and derivation of nestin/CD133 positive osteosarcoma cell lines, BMC Cancer 8 (2008), 300.

[43] R. Veselska, P. Kuglik, P. Cejpek, H. Svachova, J. Neradil, T. Loja and J. Relichova, Nestin expression in the cell lines derived from glioblastoma multiforme, BMC Cancer 6 (2006), 32.

[44] A. Weigmann, D. Corbeil, A. Hellwig and W.B. Huttner, Prominin, a novel microvillispecific polytopic membrane protein of the apical surface of epithelial cells, is targeted to plasmalemmal protrusions of non-epithelial cells, Proc Natl Acad Sci USA 94 (1997), 12425-12430.

[45] L. Yi, Z.H. Zhou, Y.F. Ping, J.H. Chen, X.H. Yao, H. Feng, J.Y. Lu, J.M. Wang and X.W. Bian, Isolation and characterization of stem cell-like precursor cells from primary human anaplastic oligoastrocytoma, Mod Pathol 20 (2007), 1061-1068.

[46] A.H. Yin, S. Miraglia, E.D. Zanjani, G. Almeida-Porada, M. Ogawa, A.G. Leary, J. Olweus, J. Kearney and D.W. Buck, AC133, a novel marker for human hematopoietic stem and progenitor cells, Blood 90 (1997), 5002-5012.

[47] M. Zhang, T. Song, L. Yang, R. Chen, L. Wu, Z. Yang and J. Fang, Nestin and CD133: Valuable stem cell-specific markers for determining clinical outcome of glioma patients, J Exp Clin Cancer Res 27 (2008), 85.

[48] Z. Zhu, X. Hao, M. Yan, M. Yao, C. Ge, J. Gu and J. Li, Cancer stem/progenitor cells are highly enriched in CD133+CD44+ population in hepatocellular carcinoma, Int J Cancer 126 (2010), 2067-2078. 


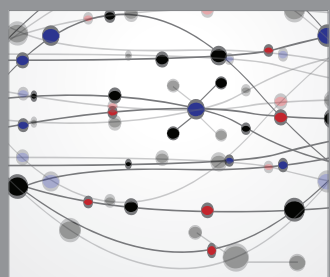

The Scientific World Journal
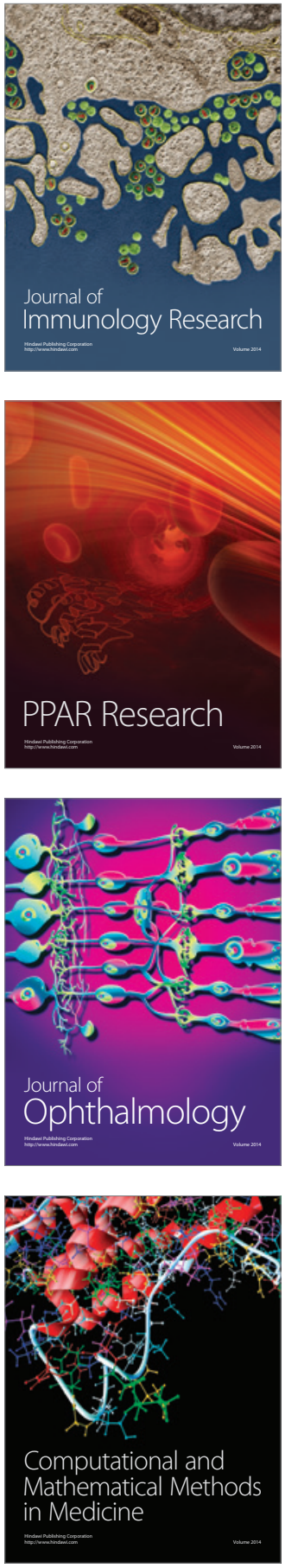

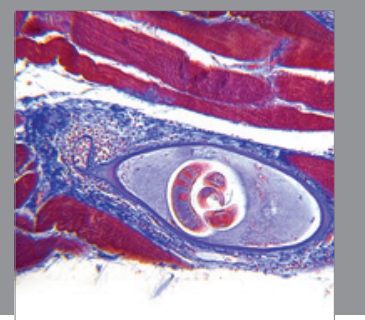

Gastroenterology

Research and Practice
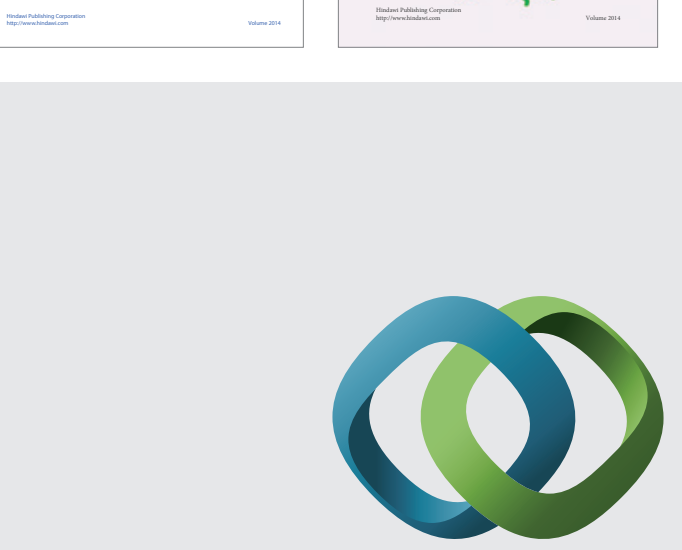

\section{Hindawi}

Submit your manuscripts at

http://www.hindawi.com
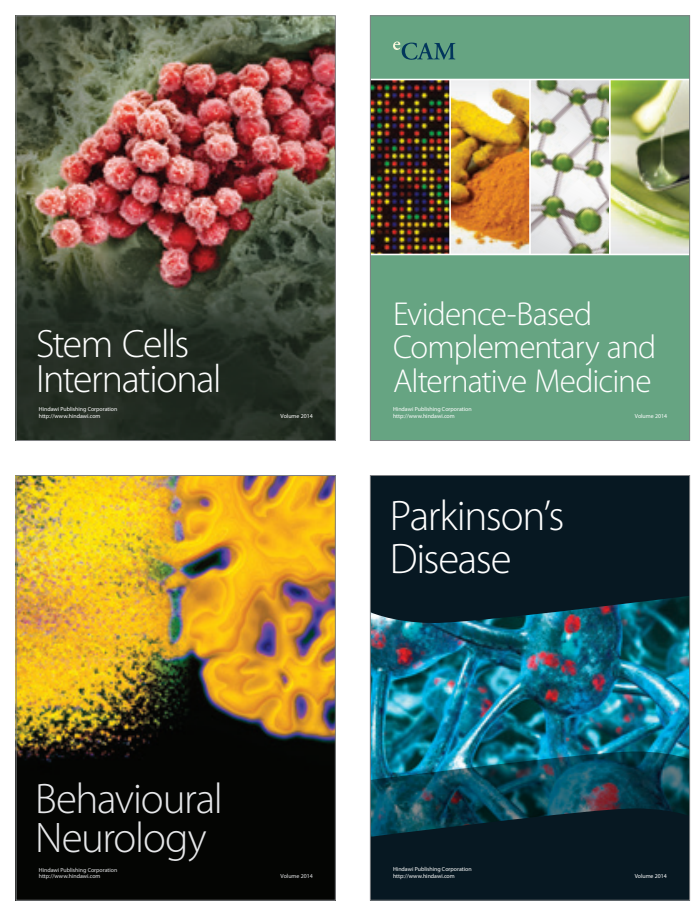

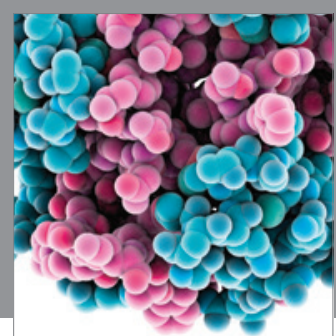

Journal of
Diabetes Research

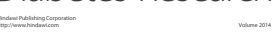

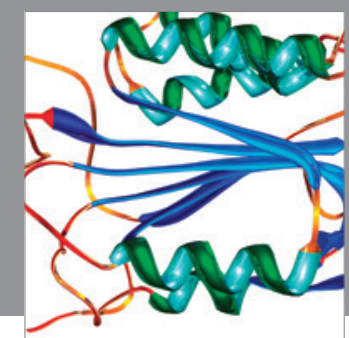

Disease Markers
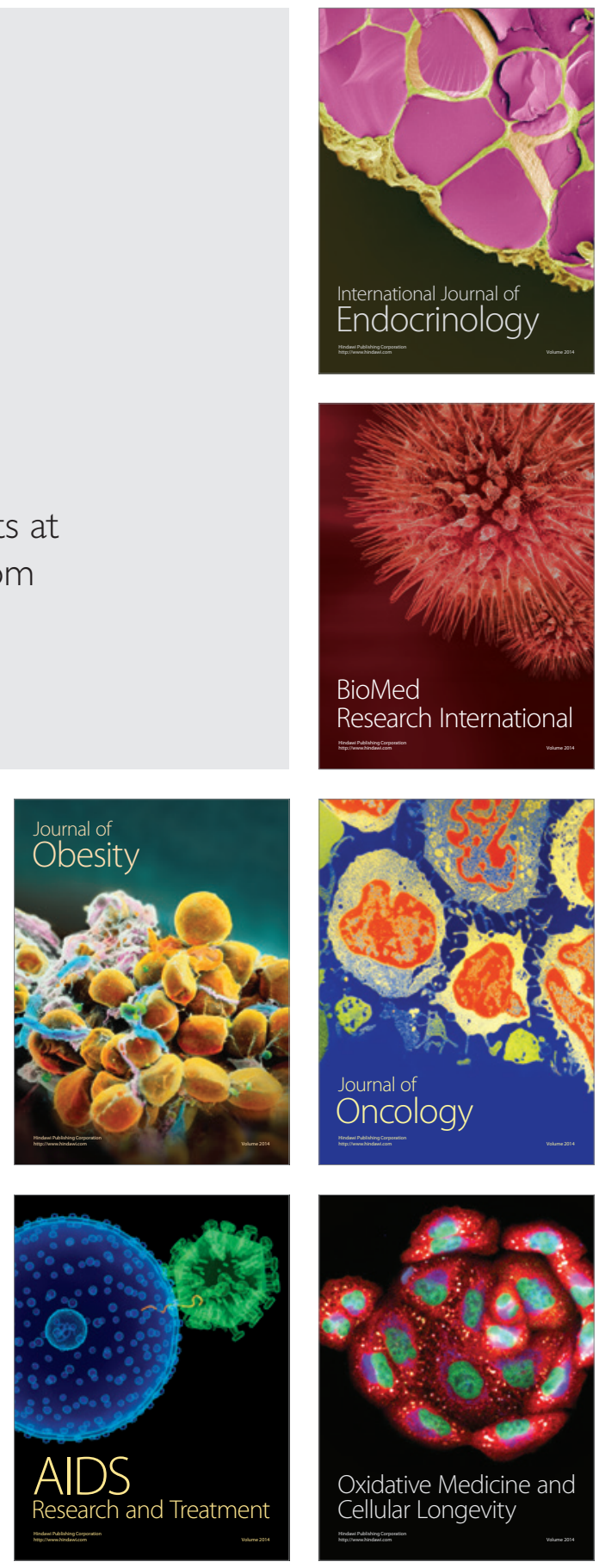